\title{
Antithrombin-III deficiency in a Dutch family
}

\author{
J. VAN DER MEER, E. A. STOEPMAN-VAN DALEN, AND J. M. S. JANSEN \\ From the Department of Blood Coagulation Research, Central Laboratory of The Netherlands Red Cross \\ Blood Transfusion Service, Amsterdam, The Netherlands
}

SYNOPSIS A Dutch family (family A) with inherited antithrombin-III deficiency and an increased $\stackrel{\circ}{\circ}$ incidence of venous thrombosis was investigated. Antithrombin-III levels were measured by means? of a coagulation assay in plasma and by single radial immunodiffusion in plasma and serum. N

Three groups could be distinguished: group I comprised the relations-in-law of family A, group: $N$ II the members of family A with a plasma antithrombin-III level higher than $90 \%$ of normal, when $\mathbb{N}_{\mathrm{N}}$ determined by the immunoassay, and group III the members of family A with an antithrombin-IIIO level of less than $60 \%$. To group III belonged all eight adults with an abnormal tendency to thrombosis, and furthermore nine children, all having a parent with abnormally low antithrombin-III $\bigodot_{\subseteq}$ levels. Mean plasma and serum antithrombin-III levels were significantly decreased in group III. $<$ However, the results of the coagulation assay showed some overlap between groups II and III. In $\vec{\varphi}$ addition, the immunoassay appeared to be much less laborious than the coagulation assay. Therefore, $\omega$ the former assay is recommended in any search for similar families.

The results of our family investigation confirm the findings of Egeberg (1965) that inherited antithrombin-III deficiency, giving rise to plasma levels between 50 and $60 \%$ of normal, causes thrombophilia and that the pattern of inheritance is autosomal dominant.

The existence of a hypercoagulable state of circulating blood predisposing to thrombosis has been extensively investigated (for a review, see Penick, 1969). Studies on subjects with an increased tendency to venous thrombosis have pointed to various plasma factors which might indicate or be the cause of hypercoagulability: inhibition of plasminogen activation (Nilsson, Krook, Sternby, Söderberg, and Söderström, 1961), antithrombin-III deficiency (Egeberg, 1965; Von Kaulla and Von Kaulla, 1967; Penick, 1969), elevated factor V levels (Gaston, 1966), circulating antibodies against fibrinogen (Mammen, Schmidt, and Barnhart, 1967), abnormal fibrinogen (Egeberg, 1967), circulating fibrin monomers (Vreeken, Fedder, Van der Meer, Van Aken, Prakke, and Goote, 1972), and deficiency of plasminogen activator (Isacson and Nilsson, 1972). In 1965 Egeberg described a Norwegian family with a high incidence of venous thrombosis. Plasma antithrombin-III (progressive antithrombin) activity was decreased to about $50 \%$ of normal in the seven adult members with a history of thrombosis and also in three unaffected children. Antithrombin-III was measured by means of a clotting assay.

In two reports from the USA similar cases have Received for publication 21 May 1973. been mentioned. Von Kaulla and Von Kaulla (1967) briefly described a father and a son, and Penick (1969) a young woman, all showing an abnormal tendency to thrombosis and low antithrombin-III levels. In both instances many (not examined) $\dot{0}$ family members had also experienced thromboembolic complications.

In the present study a large Dutch family with anti- $\overline{3}$ thrombin-III deficiency is described. Antithrombin-o III was measured by a clotting assay as well as by immunoassay.

\section{Family History and Case Reports}

Most members of family A and B (fig 1) live in స్ల Twente, an agricultural area in the eastern part of 0 The Netherlands. No foreign ancestors could be ascertained.

CASE I- 1

This 74-year-old ancestor of family A had a history of venous leg thrombosis, probably bilateral, at the $\stackrel{\odot}{\odot}$ age of 20. Since then he had suffered from severe $\vec{\otimes}$ varicose veins of both legs, but otherwise he had $\stackrel{\circ}{\circ}$ been in good health. In 1970 he had a myocardial infarction and had been given long-term coumarin 
FAMILY A

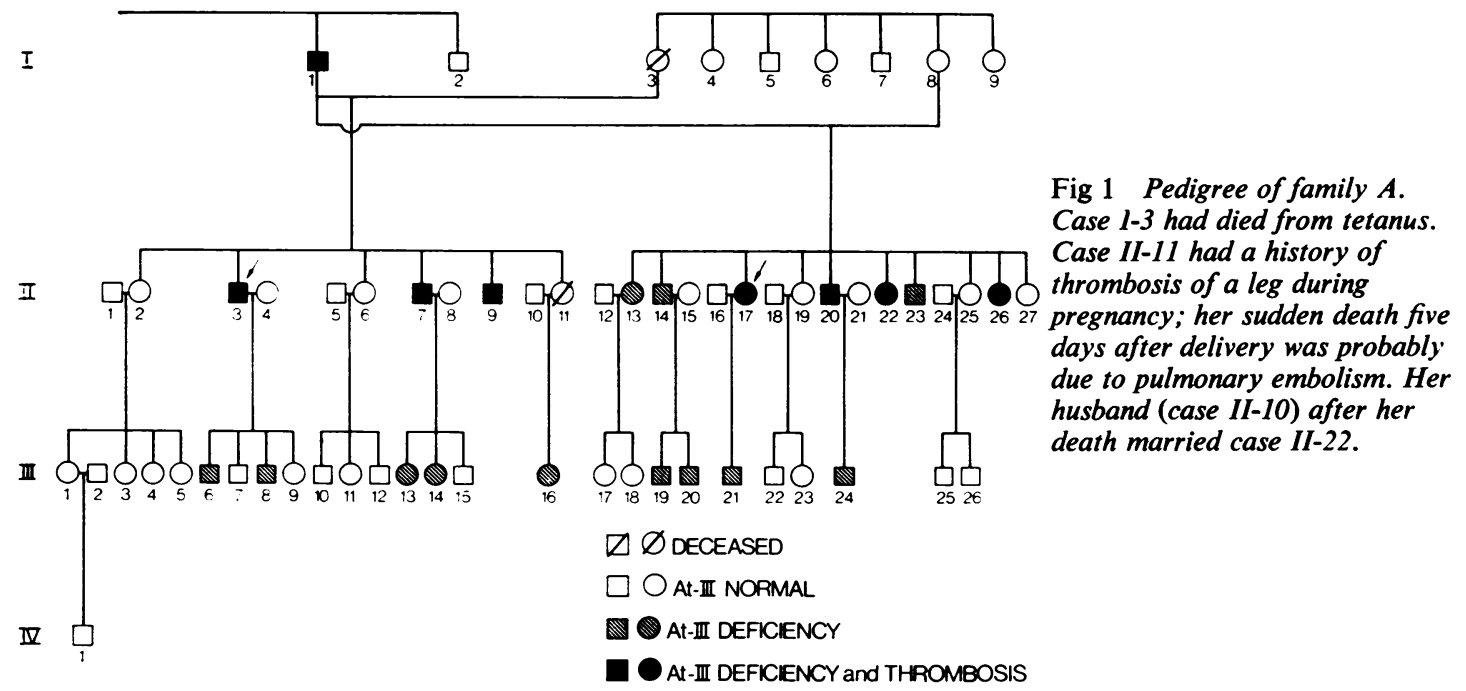

treatment. In November 1972 he died suddenly. He had been married twice: his first wife (I-3) had died from tetanus; her sister (I-8) was his second wife.

CASE II-11

This woman became pregnant for the first time in 1967 at 32 years of age. Since the first weeks of pregnancy she had a swollen, painful leg, which was not diagnosed as thrombosis and for which no anticoagulants were given. Five days after delivery she died suddenly, probably from pulmonary embolism. In this case again, the husband (II-10) married one of his first wife's half sisters (II-22), who also had thrombosis of a leg during the early part of her first pregnancy.

During the last few years more members of the second generation of family $\mathbf{A}$ have had signs and symptoms of venous thrombosis. For that reason a family investigation was started in 1972 with members II-3 and II-17.

CASE II-3

W.J.B., a 44-year-old man, had his first episode of leg thrombosis in 1969. In 1971 he had signs and symptoms of recurrent pulmonary infarction. In January 1972 thrombosis in the other leg developed. No predisposing factors such as fever, immobilization, or recent surgery had been present.

CASE II-17

B.K.-B., a 30-year-old woman, had thrombosis of the right leg in 1966 and 1970. Both times she turned out to be a few weeks pregnant. During the first pregnancy pulmonary embolism developed after temporary interruption of coumarin therapy. Further treatment with coumarin and heparin during pregnancy and the puerperium resulted in uneventful childbirth on both occasions.

In both cases normal values were obtained for haemoglobin level, whole blood clotting time, thrombin clotting time, prothrombin time, activated partial thromboplastin time, thrombelastography, ethanol gelation test, protamin sulphate titration, euglobulin clot lysis time, bleeding time, platelet count, and platelet aggregation. Quantitative assays for clotting factors II, V, VII/X, VIII, IX, and X, plasminogen and fibrin degradation products gave normal results. However, in both cases antithrombinIII levels, measured by a two-stage clotting assay (Hensen and Loeliger, 1963), were between 50 and $60 \%$ of normal.

In October 1972 a family reunion was organized, in which all members of family $A$ and their relationsin-law (except III-2) participated. From all persons present (shown in fig 1) and from three members of the second generation of family B (not shown) blood was obtained. Venepuncture failed in only two babies from family A's third generation. At the time of blood sampling all members were apparently in good health. Case II-22 was two months pregnant; she was being treated with heparin for thrombosis of a leg, which had appeared eight weeks before. In all other cases with a history of thrombosis the last episode was more than three months previously. Cases I-1 and II-26 were treated with a coumarin drug. Only two women (III-1 and III-3) used a oestrogen-containing contraceptive pill. 


\section{Materials and Methods}

Plasma was obtained from $9 \mathrm{ml}$ of blood collected in $1 \mathrm{ml}$ of trisodium citrate $3.8 \%(\mathrm{w} / \mathrm{v})$ by centrifuging for 10 minutes at $1200 \times g$. Serum was harvested after clotting of blood in glass tubes kept at $4^{\circ} \mathrm{C}$ for about 16 hours. All plasma and serum samples were given a randomly chosen code number. The samples were stored at $-40^{\circ} \mathrm{C}$. Antithrombin-III determinations were performed within three weeks after venepuncture.

\section{ANTITHROMBIN-III ASSAYS}

All antithrombin-III assays were performed in random order by one of us (Mrs E.A. S.-v.D.) without any knowledge of the clinical data.

Progressive antithrombin activity in plasma (plasma antithrombin-III coagulation)

This was determined by means of a two-step coagulation assay as described by Hensen and Loeliger (1963) after absorption with barium sulphate. No correction was made for the dilution in citrate. Each day new standard reference curves for thrombin and antithrombin-III were constructed. The results reported are the means of at least duplicate determinations. The assays yielding results between 65 and $80 \%$ of normal were repeated on another day.

As a reference a four-donor plasma pool, kept in liquid nitrogen, was used. The antithrombin-III level of this pool had been calculated from the $\frac{\bar{\sigma}}{-}$ results obtained in 22 normal adults (17 men and $\Rightarrow$ five women not using contraceptive pills). The mean $\stackrel{?}{?}$ of the antithrombin-III levels in these 22 persons was? considered to be $100 \%$ (SD $11 \%$ ).

Immunoassay of antithrombin-III in plasma and serum (plasma/serum antithrombin-III immunoassay) is Antithrombin-III antiserum was bought from Nye- $\vec{\circ}$ gaard, Oslo. The single radial immunodiffusion method of Mancini, Carbonara, and Heremans (1965) $\vec{\omega}$ was applied. Each plate contained 24 holes, five? of which were used for dilutions of the standard $\frac{8}{0}$ reference plasma mentioned above. The diameter of $\stackrel{\sim}{\circ}$ the precipitates was measured after standing for four $v$ days at $16^{\circ} \mathrm{C}$. All determinations were done in duplicate.

\section{Results}

REPRODUCIBILITY

The reproducibility of the three methods for measuring antithrombin-III was computed from the results of duplicate determinations: $\mathrm{SD}=\sqrt{\frac{\sum(a-b)}{2 n}}$, $a=$ result of first and $b=$ result of second determination, $\mathbf{n}=$ number of samples. The following standard deviations were found: plasma antithrombin-III coagulation $4.5 \%(n=79)$; plasma anti-

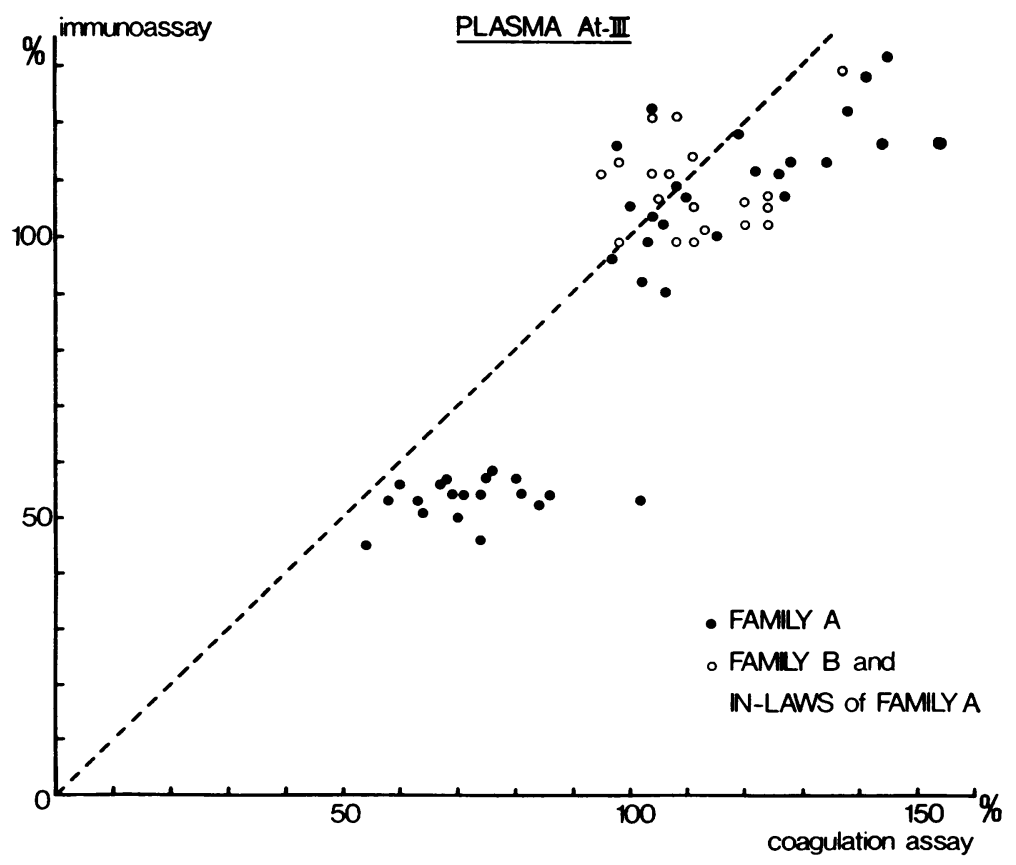

Fig 2 Relationship between results of plasma antithrombin-III determinations performed by the immunoassay and the coagulation test. A significant correlation exists between the normal results of both assays $(r=0.51$, $\mathrm{P}<0.001)$. No significant correlation was found for the group with low plasma antithrombin-III immunoassay levels. 
thrombin-III immunoassay $6.4 \%(n=61)$; serum antithrombin-III immunoassay $5 \cdot 2 \%(n=62)$. The SD of the plasma antithrombin-III coagulation assay was significantly smaller than that of the plasma immunoassay $(P<0.05$, F-distribution $)$. The reproducibility of the plasma coagulation assay did not differ significantly from that of the serum immunoassay; the same held true for the plasma immunoassay and the serum immunoassay.

\section{ANTITHROMBIN-III LEVELS}

Figure 2 shows the results of plasma antithrombinIII determinations as performed by the coagulation assay and the immunoassay. Two clusters of points can be distinguished: the upper right cluster shows all results from members of family $B$ and the relations-in-law of family $A$, whereas the lower left one contains the results of the members of family $\mathbf{A}$ with an increased tendency to venous thrombosis. The correlation coefficient for the values in the upper region was $r=0.51 \quad(P<0.001$, Student's $t$ test), no significant correlation was found for the values in the lower region.

Based on the results obtained by the immunoassay three groups could be distinguished: group I, members of family B and relations-in-law of family A; group II, members of family A, plasma antithrombin-III immunoassay $>90 \%$; and group III, members of family A, plasma antithrombin-III immunoassay $<60 \%$.

In fig 3 the results of the antithrombin-III immunoassay in plasma and serum can be compared. Both assays separated the high level and the low level group in a similar way; no overlap, as found in the comparison between plasma antithrombin-III coagulation and plasma antithrombin-III immunoassay (fig 2), was observed. Again the three above mentioned groups (I, II, and III) can be discerned. The results of the three antithrombin-III assays are given in table I. The mean values obtained in group

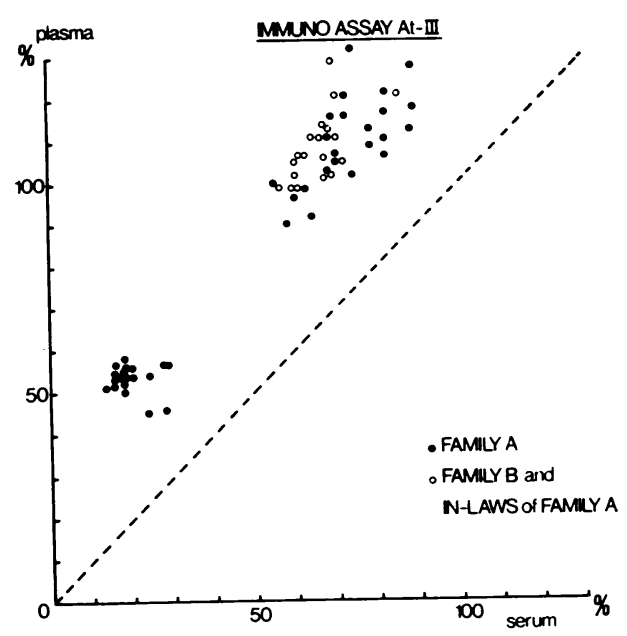

Fig 3 Relationship between plasma and serum antithrombin-III levels measured by immunoassay.

III were significantly lower than in groups I and II (P $<0.001$, Student's $t$ test).

\section{ANTITHROMBIN-III LEVELS AND HISTORY OF VENOUS THROMBOSIS}

In groups I and II a history of an episode of venous thrombosis was elicited in three out of 43 persons (table II). Taking age and clinical circumstances into account, these episodes cannot be considered to be strikingly abnormal. In group III (table III), however, eight out of 11 adults had a history of venous thrombosis; in most members the first thrombotic event happened before their 30th birthday. In cases II-17 and II-22 the appearance of thrombosis of a leg was the first sign of pregnancy. No predisposing factors were discovered in the other members with thrombosis. In case II-22 no plasma antithrombin-III coagulation assay was performed because of heparin

\begin{tabular}{|c|c|c|c|c|c|}
\hline \multirow[t]{2}{*}{ Group } & \multirow[t]{2}{*}{ Family } & & \multicolumn{3}{|l|}{ Antithrombin-III (\%) } \\
\hline & & & Plasma Coagulation Test & Plasma Immunoassay & Serum Immunoassay \\
\hline I & $\mathbf{B}$ and in-laws of family $\mathbf{A}$ & $\begin{array}{l}\text { Mean } \\
\text { SD } \\
\text { n }\end{array}$ & $\begin{array}{r}111 \\
11 \\
20\end{array}$ & $\begin{array}{r}108 \\
8 \\
19\end{array}$ & $\begin{array}{r}66 \\
6 \\
20\end{array}$ \\
\hline II & $\begin{array}{l}\text { A Plasma antithrombin-III immunoassay } \\
>90 \%\end{array}$ & $\begin{array}{l}\text { Mean } \\
\text { SD } \\
\text { n }\end{array}$ & $\begin{array}{r}119 \\
17 \\
23\end{array}$ & $\begin{array}{r}110 \\
11 \\
23\end{array}$ & $\begin{array}{l}73 \\
10 \\
23\end{array}$ \\
\hline III & $\begin{array}{l}\text { A Plasma antithrombin-III immunoassay } \\
<60 \%\end{array}$ & $\begin{array}{l}\text { Mean } \\
\text { SD } \\
\text { n }\end{array}$ & $\begin{array}{l}72 \\
11 \\
19\end{array}$ & $\begin{array}{r}52 \\
7 \\
20\end{array}$ & $\begin{array}{r}20 \\
4 \\
19\end{array}$ \\
\hline
\end{tabular}

Table I Results of antithrombin-III determinations in 63 members of families $A$ and $B$ and relations by marriage of family $A^{1}$

${ }^{1}$ Mean plasma and serum antithrombin-III levels in group III were significantly lower than in groups I and II (P < 0.001$)$ 


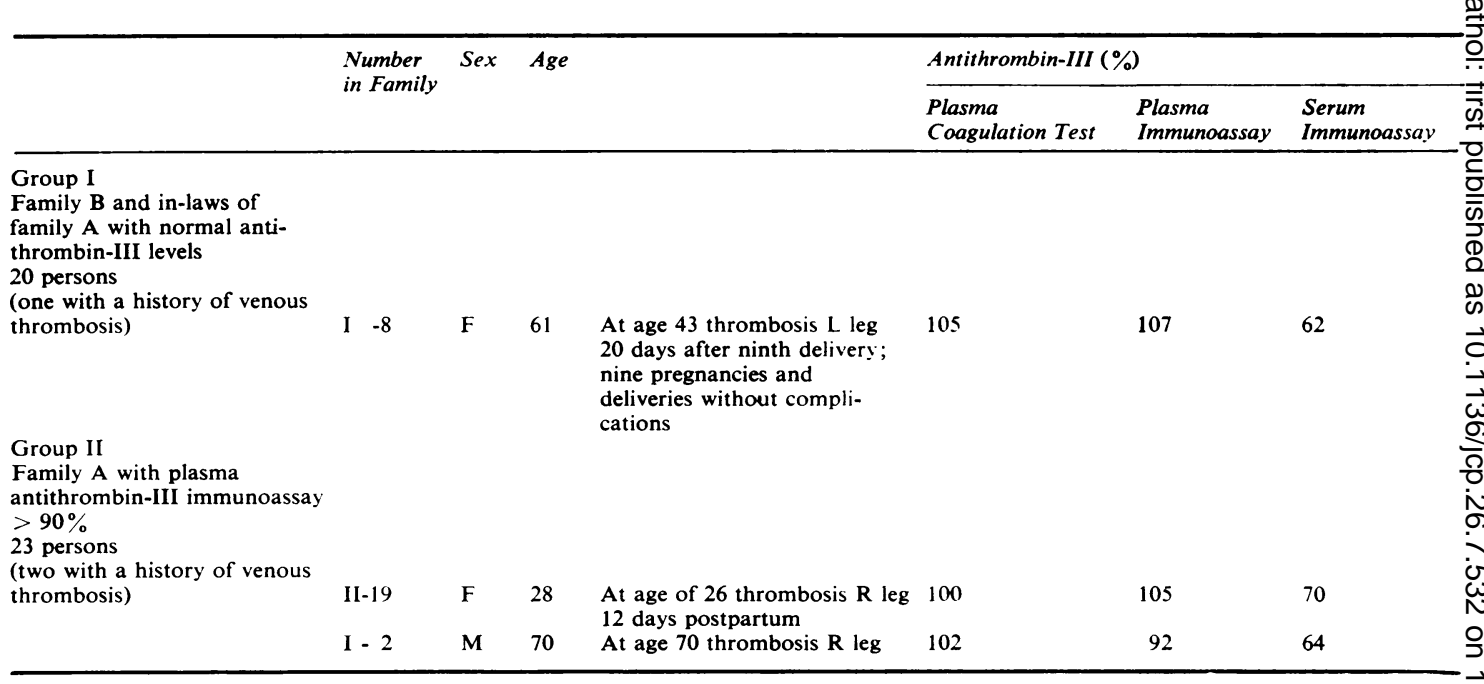

Table II Episodes of venous thrombosis in persons with normal plasma antithrombin-III immunoassay levels

treatment; her exceptionally low immunochemical antithrombin-III levels in serum and plasma might be due to the combined influence of pregnancy and recent thrombosis. Cases I-1 and II-9 had relatively high plasma antithrombin-III levels with the coagulation assay in contrast to the results of the immunoassay.

ANTITHROMBIN-III AND AGE

Plasma antithrombin-III levels tended to be higher in the lower age groups (figs 4 and 5). The corre- lation was only significant in persons with plasmaw antithrombin-III immunoassay levels higher than $90 \%$ (groups I and II). With the coagulation assay? (fig 4) the correlation coefficient $r$ was -0.36 ( $\mathrm{P}<\frac{\mathrm{D}}{\mathrm{O}}$ 0.02 ) and for the immunoassay (fig 5) $r$ was -0.420 $(P<0.01)$. In the low level group (group III) ro values were not significantly different from 0 .

GENETICS

From inspection of the pedigree in fig 1 it can be

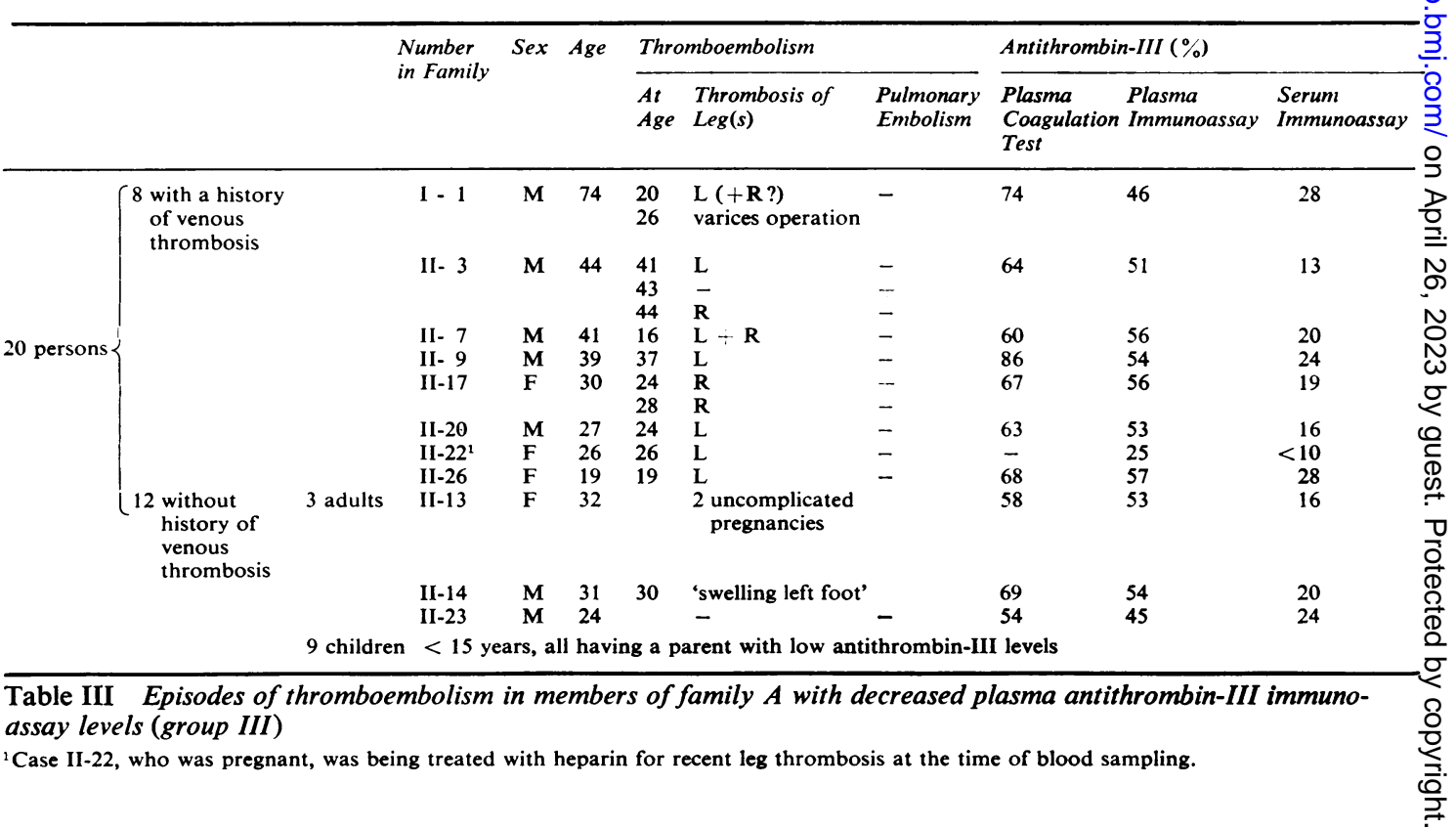




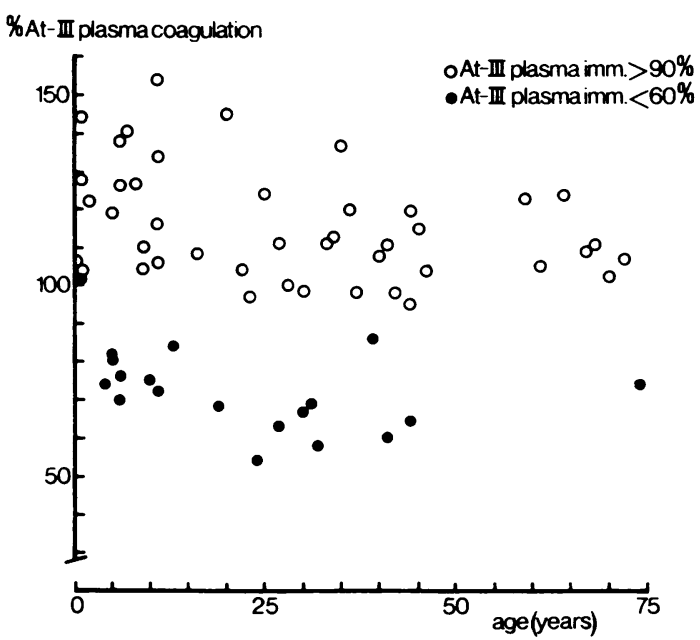

Fig 4 Relationship between age and plasma antithrombin-III levels measured by coagulation assay. Correlation coefficient for open circles: $r=-0 \cdot 36$, $\mathbf{P}<0.02$. No significant correlation for closed circles.

concluded that the pattern of inheritance of the disorder is autosomal dominant.

\section{Discussion}

The members of family A could be divided into two groups by means of the immunoassay for antithrombin-III (figs 2 and 3). The low level group (group III, table III) comprised the eight members with a pronounced tendency to venous thrombosis. All had more or less severe signs and symptoms of venous insufficiency in the affected leg(s) at the time of investigation. Two women (II-17 and II-22) had developed thrombosis of a leg as soon as they became pregnant, which is obviously an abnormal finding. The incidence of thrombosis during pregnancy, and especially in the puerperium, is increased, but usually this complication occurs within 14 days following delivery or during the last trimester of pregnancy (McDevitt and Smith, 1969). No predisposing factors existed in the other six members, some having developed thrombosis before the age of 20 .

A low antithrombin-III concentration in blood does not inevitably give rise to thrombosis: case II-13 (plasma antithrombin-III immunoassay $53 \%$, table III) had two uneventful pregnancies, and two more adult members with low antithrombin-III levels had no convincing history of thrombosis. The thrombotic episodes in members of family A and B with normal antithrombin-III levels cannot be considered to be expressions of thrombophilia (table II).

Our data corroborate Egeberg's findings (1965) that inherited antithrombin-III deficiency is an

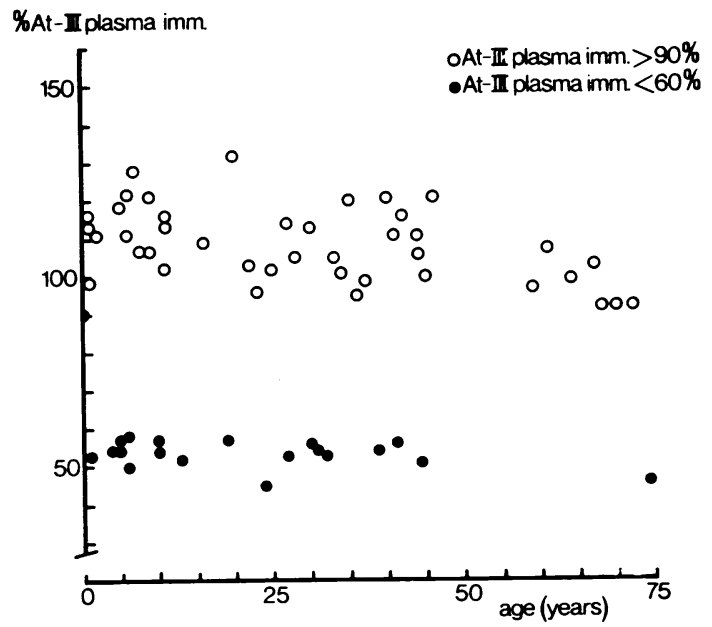

Fig 5 Relationship between age and plasma antithrombin-III levels measured by immunoassay. Correlation coefficient for open circles: $r=-0.41, \mathrm{P}<0.02$. No significant correlation for closed circles.

autosomal dominant disorder predisposing to venous thrombosis. However, the seven affected members of the Norwegian family had their first thrombotic episode at ages varying between 10 and 25 , whereas in some adults of the Dutch family this happened much later or not at all. The ancestor of family A (I-1) had only one thrombotic complication during his long life. The unusual large size of family A, whose members mostly live in the same area, greatly facilitated the discovery of the disorder, which in other circumstances might have escaped attention. Conceivably, the incidence of inherited antithrombinIII deficiency is higher than might be concluded from the scanty reports in the literature (Egeberg, 1965; Von Kaulla and Von Kaulla, 1967; Penick, 1969). As oestrogen-containing contraceptives may decrease serum and plasma antithrombin-III levels (Von Kaulla and Von Kaulla, 1970; Fagerhol and Abildgaard, 1970; Gjønnaess and Fagerhol, 1971), these drugs must be avoided in women with antithrombin-III deficiency. Therefore, antithrombin-III determinations should be performed in women with a family history of thrombosis before oestrogencontaining drugs are prescribed.

From a comparison of figs 2 and 3 and tables II and III, it can be seen that the antithrombin-III immunoassay was more suitable than the coagulation assay to separate normal from abnormal members of family A. Two members with a history of thrombosis in group III (I-1 and II-9, table III) had plasma antithrombin-III coagulation levels that were not definitely abnormal; their antithrombin-III immunoassay levels, however, were abnormally low. 
In addition, the immunoassay is much less timeconsuming than the coagulation assay. The difference between the results of both methods could not be ascribed to a better reproducibility of the immunoassay.

Antithrombin-III levels decrease with age as has been observed by Hensen and Loeliger (1963) and Egeberg (1965) for the plasma coagulation assay and by Fagerhol and Abildgaard (1970) for the serum immunoassay. Our results of the plasma immunoassay in normal persons show the same tendency (fig 5 ). The influence of age on antithrombin-III levels seems to be less clear in persons with antithrombin-III deficiency, especially when determined by the plasma immunoassay (figs 4 and 5).

A positive correlation was found between the results of the coagulation and the immunoassay in plasma of normal persons (fig 2), which is in agreement with Abildgaard, Fagerhol, and Egeberg (1970). In contrast to our results, these investigators also found a positive correlation in a group with low antithrombin-III levels. However, their low-activity group of 23 individuals contained only three cases of hereditary antithrombin-III deficiency, which might have caused this discrepancy. Egeberg (1965) suggested that antithrombin-III and heparin-cofactor activity are properties of the same plasma substance. Fagerhol and Abildgaard (1970) found that the addition of antithrombin-III antibodies to human serum or plasma reduced the antithrombin-III level, as measured by means of a coagulation assay, by about $70 \%$ and abolished the heparin-cofactor activity. This suggests, that in the coagulation assay more antithrombin activity is measured than can be ascribed to antithrombin-III or heparin-cofactor, and that the discrepancy in our low antithrombin-III level group between the results of the coagulation assay and the immunoassay is caused by another antithrombin activity. This antithrombin activity might be due to $\alpha_{2}$-macroglobulin $\left(\alpha_{2}-\mathrm{M}\right)$ : members of family A with the largest difference between the antithrombin-III coagulation assay and the immunoassay also showed the highest $\alpha_{2}$-M levels as measured with a single radial immunodiffusion method (unpublished results).

The results of this family investigation suggest that the immunoassay is superior to the coagulation assay in distinguishing normal from antithrombin-IIIdeficient members. During clotting of blood in vitro from healthy persons the immunochemically assayable antithrombin-III concentration decreases by about 30 to $40 \%$ (Fagerhol and Abildgaard, 1970), suggesting that thrombin blocks antigenic sites on the antithrombin-III molecule. A similar reduction was also observed in the affected members of family A (fig 3 and table I). Theoretically, variations in plasma prothrombin level might influence the magnitude of the decrease in antithrombin-III concentration during clotting in vitro. For that reason we recommend the plasma immunoassay for the search of families with antithrombin-III deficiency.

We should like to thank Miss M. van Dooren, Dr W Gerrits, and our colleagues in Twente for their help in organizing this family investigation.

References

Abildgaard, U., Fagerhol, M. K., and Egeberg, O. (1970). Comparison of progressive antithrombin activity and the concentrations of three thrombin inhibitors in human plasma. Scand. J. clin. Lab. Invest., 26, 349-354.

Egeberg, O. (1965). Inherited antithrombin deficiency causing thrombophilia. Thrombos. Diathes. haemorrh. (Stuttg.), 13, 516-530.

Egeberg, O. (1967). Inherited fibrinogen abnormality causing thrombophilia. Thrombos. Diathes, haemorrh. (Stuttg.), 17, 176-187.

Fagerhol, M. K., and Abilgaard, U. (1970). Immunological studies on human antithrombin. III. Influence of age, sex, and use of $\omega$ oral contraceptives on serum concentration. Scand. J. Haemat. $7,10-17$

Gaston, L. W. (1966). Studies on a family with an elevated plasma level of factor $\mathbf{V}$ (proaccelerin) and a tendency to thrombosis J. Pediat., 68, 367-373.

Gjønnaess, H., and Fagerhol, M. K. (1971). Plasma concentrations of anti-thrombin III in untreated and estrogen-treated puerperal women. In Proceedings of the 2 nd Congress of the International Society on Thrombosis and Haemostasis, Oslo, p. 20.

Hensen, A., and Loeliger, E. A. (1963). Antithrombin III: its metabolism and its function in blood coagulation. Thrombos. Diathes. haemorrh. (Stuttg.), 9, Suppl. 1.

Isacson, S., and Nilsson, I. M. (1972). Defective fibrinolysis in blood and vein walls in recurrent 'idiopathic' venous thrombosis Acta chir. scand., 138, 313-319.

Von Kaulla, E., and Von Kaulla, K. N. (1967). Antithrombin III and diseases. Amer. J. clin. Path., 48, 69-80.

Von Kaulla, E., and Von Kaulla, K. N. (1970). Oral contraceptives and low antithrombin-III activity. (Letter). Lancet, 1, 36.

McDevitt, E., and Smith, B. (1969). Thrombophlebitis during O pregnancy and the puerperium. In Thrombosis, edited by $\mathrm{S} . ?$ Sherry, K. M. Brinkhous, E. Genton, and J. M. Stengle, pp. 55-56. National Academy of Sciences, Washington, D.C.

Mammen, E. F., Schmidt, K. P., and Barnhart, M. I. (1967). Thrombo- $\square$ phlebitis migrans associated with circulating antibodies against음 fibrinogen: a case report. Thrombos. Diathes. haemorrh. (Stuttg.), 18, 605-611.

Mancini, G., Carbonara, A. O., and Heremans, J. F. (1965). Immunochemical quantitation of antigens by single radial immuno- $\mathrm{N}$ diffusion. Immunochemistry., 2, 235-254.

Nilsson, I. M., Krook, H., Sternby, N. H., Söderberg, E., and N Söderström, N. (1961). Severe thrombotic disease in a young $\omega$ man with bone marrow and skeletal changes and with a high $\sigma$ content of an inhibitor in the fibrinolytic system. Acta med scand., 169, 323-337.

Penick, G. D. (1969). Blood states that predispose to thrombosis. In Thrombosis, edited by S. Sherry, K. M. Brinkhous, E. Genton, $\stackrel{\mathscr{C}}{+}$ and J. M. Stengle, pp. 553-565. National Academy of Sciences, $\square$ Washington, D.C.

Vreeken, J., Fedder, G., van der Meer, J., van Aken, W. G., Prakke, $\stackrel{ }{\square}$ E. M., and Goote, T.M. (1972). Some initial aspects of diffuse (D) intravascular coagulation and its relation to the 'pre-thrombotic $\frac{{ }_{(D)}}{(\mathrm{d}}$ state'. In Proceedings of the 3rd Congress of the International 2 Society on Thrombosis and Haemostasis, Washington, pp. 348. 